\title{
Tempo subjetivo e percepção de movimento em obras de arte
}

\author{
Francisco Carlos Nather \\ José Lino Oliveira Bueno \\ Universidade de São Paulo - Ribeirão Preto
}

\begin{abstract}
Resumo
O estudo de imagens em movimento e de imagens estáticas que representam algum movimento contribui para o esclarecimento do papel do tempo como modulador da experiência humana. Diferentes formas de representar ou induzir movimento em estímulos ou distintas obras das artes visuais devem envolver não somente técnicas específicas, mas diferentes formas de interação que só ocorrem quando se dá o encontro entre obra e expectador. A percepção de movimento, muito provavelmente, não está confinada a uma simples decomposição ou soma das suas grandezas constituintes (tempo, espaço e velocidade), pois na sua cognição estão combinadas sensações e percepções internas e externas, que ocorrem em sistemas e níveis perceptuais distintos. Entretanto, processos correlatos devem responder pela percepção de movimentos reais, induzidos e representados. Sendo oriundo da intersecção espaço-temporal, a utilização do movimento em pesquisas de estética experimental pode contribuir para o esclarecimento dos processos que atuam na percepção subjetiva de tempo.

Palavras-chave: tempo subjetivo; movimento; imagens; artes plásticas
\end{abstract}

\begin{abstract}
Subjective time and perception of movement in art works. The study of images in movement as well as those static images, which represent some movement, contributes to the understanding of the role of time as a modulator of the human experience. Different forms of representing and inducing movement in stimuli or in distinct works of visual art shall involve not only specific techniques, but different forms of interaction which only occur when there is an encounter between the work of art and the spectator. The perception of movement, probably, is not confined to a unique decomposition or sum of its constituent greatnesses (time, space and speed), thus in its cognition the internal and external sensations and perceptions are combined, which occur in distinct systems and perceptual systems. Nevertheless, correlated processes shall respond by the perception of real movements, induced and represented ones. Having come from the intersection of temporal space, the utilization of movement in studies of experimental aesthetics can contribute to the understanding of the processes that act in the subjective perception of time.
\end{abstract}

Key words: subjective time; movement; images; visual arts

$\mathrm{U}$ ma maneira de explicar o fenômeno estético é por meio da estética psicobiológica, na qual está inserida a estética experimental, originalmente definida por Gustav Fechner em 1876. A visão mais contemporânea da estética, a Nova Estética Experimental (Berlyne, 1974) estabelece como estudar obras de arte ou outros fenômenos estéticos, por meio de experiências que analisam as reações dos sujeitos aos estímulos artísticos. Esta área de pesquisa se caracteriza especialmente pela análise das relações entre variáveis independentes (trechos musicais, pinturas, desenhos, etc.) e variáveis dependentes (relatos verbais, medidas psicofisiológicas e comportamentais, etc.). Tais análises ex- perimentais comportam, também, elementos teóricos importantes para a compreensão dos processos subjacentes à apreciação artística.

Nas artes visuais, obras bidimensionais podem gerar diferentes experiências de movimento no observador. Essa experiência está estreitamente vinculada a uma modulação temporal que ocorre durante o encontro entre o observador e a obra de arte. A identificação dos fatores que afetam a percepção de movimento em imagens bidimensionais pode ser importante em estudos que procuram desvendar o processo relacionado à experiência subjetiva de tempo durante o evento obra de arte-expectador. 
Neste estudo serão examinados aspectos gerais da percepção de movimento em imagens em movimento e em obras de artes visuais figurativas que representam movimentos. Inicialmente, é preciso que seja considerada a importância das grandezas velocidade, espaço e tempo na percepção visual de movimento. Estas têm um papel relevante em um meio onde o movimento não existe fisicamente, mas pode estar representado, como em pinturas, fotografias, desenhos. $\mathrm{O}$ presente estudo examina, especialmente, aspectos da percepção subjetiva de tempo em relação a estímulos visuais bidimensionais em movimento e em relação àqueles que representam diferentes movimentos.

\section{Aspectos gerais da percepção de movimento}

É provável que o movimento seja um dos parâmetros mais importantes da percepção do mundo físico, pois na sua cognição estão combinadas sensações e percepções internas e externas, que ocorrem em sistemas e em diferentes níveis perceptuais. A distinção entre o que muda ou se move e o que permanece constante envolve aprendizado, memória e representações mais ou menos objetivas do espaço-tempo tridimensional.

A percepção de movimento é um tópico central do desenvolvimento da percepção em humanos, antecedendo o surgimento de habilidades motoras (Kellman, 1995). Uma vez que o ambiente externo é fonte primária de aprendizado, é importante que os aspectos mutáveis e os imutáveis do ambiente (forma e plano espacial) sejam apreendidos quando, nos primeiros meses de vida, explora-se ativamente o ambiente com os olhos. Os bebês são especialmente capturados pelo movimento, tendendo a preferir eventos que se movem às cenas estáticas, porque nestes eventos podem ser colhidas diversas informações a respeito do espaço e das coisas.

Praticamente tudo que é interessante no mundo se move (Ehrenstein, 2003). A mais importante e poderosa dimensão de estímulo visual deve ser o movimento: mesmo quando um objeto está parado, sua imagem na retina pode mover, uma vez que os olhos e a cabeça nunca permanecem inteiramente parados. Isso quer dizer que o movimento pode ser real ou aparente; oriundo de algo que se desloca no espaço tridimensional ou de mecanismos de percepção que se relacionam à visão bidimensional da retina. O movimento pode também surgir do monitoramento das características físicas dos eventos pelo próprio sistema visual ou pela maneira como os elementos de uma imagem estão dispostos espacialmente.

Segundo Grondin (2003), quando se está parado, observando algo em movimento, sinais de várias localizações do espaço chegam ao sistema visual e variações na duração, intensidade e no tempo entre estes sinais visuais podem também criar uma sensação de movimento. Para a compreensão da percepção da visão deve-se levar em conta a existência de uma variedade de níveis entre a retina e as células corticais ativas em eventos visuais. O processamento de estímulos visuais apresentados em diferentes intervalos de tempo e de espaço, por exemplo flashes de luzes, pode dar a impressão de um movimento verdadeiro, denominado movimento aparente ou também chamado de movimento estroboscópico.

Tanto as características físicas dos movimentos quanto as combinações de distintos elementos num espaço físico podem sugerir movimento, porque o processamento de movimento envolve distintas áreas encefálicas. Assincronias na percepção de diferentes atributos de uma imagem têm indicado que, quando são usados estímulos geométricos em imagens bidimensionais, o movimento é percebido após a percepção da cor e da forma (Bedell, Chung, Ogmen, \& Patel, 2003; Viviani \& Aymoz, 2001). Mas, embora evidências neuroanatômicas e fisiológicas mostrem que diferentes módulos autônomos do cérebro alcancem as suas percepções em diferentes tempos, tal assincronia desaparece quando é processada uma imagem com algum significado. O processamento de tempo para a cor, forma e movimento passou a ser quase idêntico quando foi utilizada como estímulo a imagem de uma mão pegando um objeto que podia mudar de forma ou de cor (Aymoz \& Viviani, 2004). A representação figurativa de algo real do mundo tridimensional, como o filme de alguém movimentando uma parte do seu corpo, sobrepujou respostas puramente perceptuais estudadas principalmente no campo da psicofísica, revelando outros processos envolvidos na percepção de movimento.

Um grupo de células corticais, os neurônios espelho (Gallese, Fadiga, Fogassi, \& Rizzolatti, 1996; Rizzolatti, Fadiga, Gallese, \& Fogassi, 1996), pode também participar da percepção de movimento. Localizados em áreas corticais específicas, estes neurônios respondem pela percepção e interpretação de movimentos, ativando estruturas corporais envolvidas com as ações humanas: é possível dizer que a visão de um movimento humano gera uma atividade neuronal semelhante àquela de apenas observar esta ação sendo executada por outra pessoa (Gallese, Fadiga, Fogassi, \& Rizzolatti, 2002). É como se, internamente, a própria percepção visual de movimento gerasse a experiência do movimento visto, percebido e processado.

Estudos sobre percepção de movimento devem levar em consideração seus diferentes níveis de processamento. A percepção de movimento também ocorre quando o observador está se movendo: mover-se através do ambiente também gera conseqüências na própria percepção visual do movimento (Cutting, 2000). Estar em movimento origina o chamado fluxo óptico e influencia a percepção do movimento de maneira distinta daquela em que o observador está parado e visualizando algo movendo no mundo tridimensional, assistindo a exibição de um filme ou participando de um experimento em que estímulos em movimento são apresentados em uma tela de computador.

Estas considerações mostram que na percepção de movimento estão envolvidos diferentes níveis de processamento, que não dependem exclusivamente de me- 
canismos relacionados à visão. Por exemplo, como e de que maneira os parâmetros físicos que constituem os movimentos (velocidade, aceleração, direção, etc.) seriam percebidos e processados quando um observador está parado e visualizando algo em movimento? Qual seria a participação de cada um destes parâmetros físicos na percepção visual de movimento?

É importante discorrer a respeito de como a ciência vem propondo explicações e mostrando quais são os recursos utilizados por humanos durante a percepção do movimento. Muitos dos estudos nesta área têm utilizado imagens de figuras em movimento para compreender a percepção de movimentos reais. Os diferentes procedimentos experimentais têm elucidado o papel da velocidade, do espaço e do tempo em movimentos reais e em movimentos induzidos ou extrapolados. Na verdade, estes estudos têm explicado como se processa a percepção visual de movimento bidimensional.

\section{A percepção visual do movimento bidimensional}

Medidas temporais. Pontos, manchas, quadrados ou círculos movendo-se horizontalmente com uma velocidade constante têm sido utilizados em pesquisas de percepção de movimento por meio do que é denominado movimento extrapolado. Um estímulo apresentado numa tela de computador, em algum ponto da trajetória, desaparece; é pedido ao observador que julgue quando esse estímulo alcançaria um ponto determinado do espaço se ele não tivesse desaparecido ou se ele fosse reaparecer. A esse julgamento, a essa forma de predizer ou extrapolar um movimento real têmse referido como tempo de chegada, que é obtido a partir da extrapolação do movimento do objeto após o seu desaparecimento. Em alguns estudos, o sujeito tem de imaginar o percurso total do estímulo; neste caso, não é a imagem do objeto que é criada, mas a ilusão de um movimento. Geralmente, os tempos de experimentação total e os tempos de chegada são curtos, com valores que chegam há alguns segundos (Hellmann, 1996).

Implicitamente, nos trabalhos com movimento estão envolvidas necessariamente duas grandezas: o espaço, que pode ser tomado como a distância ou trajetória percorrida pelo estímulo; e o tempo, que pode ser uma medida direta (tempo real do experimento) ou a previsão de um tempo de chegada de um estímulo num local determinado. Além dessas grandezas, a velocidade do estímulo, a aceleração e o sentido (orientação do movimento) caracterizam os movimentos. Tais elementos podem explicar porque em alguns estudos o tempo de chegada pode ser utilizado como uma medida de movimento extrapolado.

O tempo de chegada, uma medida temporal que leva em conta uma perspectiva temporal, vem sendo utilizado em estudos de percepção visual de imagens em movimento. Provavelmente, medidas objetivas de passagem de tempo também ocorram em julgamentos de movimentos imaginados, mas não podem ser negligenciadas as possíveis diferenças entre a visualização de algo em movimento e o que é obtido através de uma extrapolação por cognição interna ou representação de um movimento.

Além dessa consideração a respeito dos estudos de movimento, é importante ressaltar como as tarefas apresentadas aos sujeitos podem levantar dados não concordantes. Por exemplo, julgar o movimento ou o tempo de movimento de um objeto que se movimenta realmente ou imaginar esse movimento pode elucidar distintos processos cognitivos.

Alguns estudos que procuram esclarecer como o movimento é percebido têm utilizado uma medida temporal de mensuração. Faz-se necessário explanar a respeito de como os pesquisadores vêm elucidando o papel dos outros parâmetros físicos (velocidade, aceleração etc.) na percepção de movimento.

O papel da velocidade. É difícil destacar separadamente a participação de cada grandeza na percepção de movimento. Os trabalhos têm apontado a contribuição de cada uma, porém relacionando-as umas às outras. Lappin, Harm e Kottas (1975) verificaram que a percepção da velocidade de um estímulo não é diretamente derivada da discriminação espacial e das suas posições temporais anteriores, embora ambas estejam perceptualmente relacionadas. A velocidade seria diretamente percebida, e o sistema visual possuiria um "método estereotipado" para predizer o deslocamento através da observação real do movimento (Runeson, 1975). Rosenbaum (1975) propôs que a velocidade e a aceleração são direta e apuradamente percebidas, sendo que para a velocidade a visualização do movimento é fundamental.

Ellingstad e Heimstra (1969) já haviam verificado o significativo efeito da velocidade do movimento nas estimativas de tempo: quanto maior a velocidade, mais precisa a estimação temporal. Entretanto, tanto estes autores quanto Morin, Grant e Nystrom (1956) e Alderson e Whiting (1974) sugeriram que o tempo total em que as predições são feitas é a variável mais importante. A predição de movimento seria mais influenciada pela parte de movimento que o sujeito não usa ou não vê, do que pela parte que ele usa (vê).

Segundo Nakayama (1985), que realizou uma revisão detalhada a respeito do processamento de imagens em movimento, o sistema visual possui mecanismos especializados para detectar movimento em imagens ópticas. A informação de movimento ocorre de uma ampla fonte de tarefas visuais, tais como: reconstrução da terceira dimensão do objeto em movimento, segmentação da imagem, direção dos movimentos oculares, atenção eliciada, codificação do próprio movimento, constância no tamanho dos estímulos e detecção dos tipos de movimentos. Foi apontada a existência de mais de um sistema de movimento e sugerido que, em trabalhos futuros, devam ser utilizadas técnicas de manipulação de estímulos que meçam outras coisas além da própria detecção de movimento para determinar os graus de participação desses sistemas em relação às diferentes funções visuais. 
Algom e Cohen-Raz (1987) trabalharam com a ausência de informação visual, pedindo aos sujeitos que julgassem a velocidade de movimentos reais e que, mentalmente, também construíssem movimentos de pontos parados e separados por certa distância. Comparando julgamentos ditos reais com julgamentos cognitivos (oriundos de informações sobre a distância e a duração do movimento), os autores apontaram que a percepção da velocidade parece ser diferenciada nos dois caminhos: na estimação real pode-se dizer que a velocidade é o espaço pelo tempo, mas na estimação cognitiva, a velocidade é o espaço menos o tempo. Quando um movimento não real é sugerido e a sua construção cognitiva é feita, a velocidade aparente deste movimento é menor (subestimada), quando comparada com aquela do movimento real.

Mesmo apresentando objetivos e procedimentos diferentes, os estudos apontam para uma característica fundamental na percepção do movimento: a velocidade de um movimento é percebida diretamente (Algom \& Cohen-Raz, 1987; Lappin et al., 1975; Rosenbaum, 1975; Runeson, 1975) e, para que isso ocorra, há necessariamente uma avaliação do espaço percorrido por determinado intervalo de tempo.

De acordo com Peterken, Brown e Bowman (1991), a velocidade do movimento pode ser percebida e codificada diretamente, mas a informação direta da velocidade parece não ser necessária para a predição acurada deste movimento, pois os sujeitos podem ser capazes de inferir a velocidade a partir da informação temporal e espacial. Tais autores verificaram que o intervalo temporal é mais significativo na predição temporal de movimento que o "intervalo espacial”.

Leisler, Stern e Meyer (1991), que estudaram os efeitos da velocidade média e do tempo na simulação de rotas, verificaram que segmentos espaciais curtos ocasionaram superestimações temporais; o inverso ocorreu nos segmentos longos. Para a estimação da velocidade, a recordação dos segmentos individualizados foi fundamental, mas a proporção velocidade-tempo das rotas pareceu influenciar as estimações dos participantes: trechos com velocidades pequenas e intervalos curtos foram superestimados e trechos com velocidades rápidas e períodos longos subestimados. Além disso, todas as velocidades foram subestimadas em razão do efeito de adaptação ao procedimento experimental porque, segundo os autores, um efeito de memória permeia experimentos dessa natureza.

Diferenças subjetivas de julgamento, estratégias, aptidões individuais e comportamento podem explicar as diferenças nos resultados de estudos que utilizam tempos de chegada para compreender a percepção de movimento (Yakimoff, Mateef, Ehrenstein, \& Hohnstein,1993). Brown (1995) sugeriu que essas diferenças são também devidas à sofisticação das técnicas metodológicas empregadas. Segundo o autor, para análise e interpretação de estudos de percepção de movimento deve-se levar em consideração: os tipos de estímulos usados (pontos, círculos, manchas, etc.); o tipo de movimento empregado (real ou imaginado); a orientação e trajetó- ria do movimento; os tipos de julgamentos temporais adotados (relativos e absolutos); o tamanho do campo visual; a velocidade (com ou sem aceleração); e as durações de percurso dos movimentos.

Pesquisas nessa área vêm procurando explicar como se processa a percepção do movimento no plano bidimensional e mostraram que várias características de um evento em movimento são conjuntamente avaliadas pelo observador. Provavelmente, elas devam funcionar como marcações físicas ou fornecer pontos de referência para o julgamento de movimento. Seriam essas marcações utilizadas na percepção de um movimento representado em uma imagem bidimensional estática? Semelhantes processos de percepção de movimento seriam ativados quando observadores fossem expostos a imagens estáticas de movimentos humanos paralisados? Obras de arte do tipo pinturas, fotografias e esculturas representando movimentos em diferentes intensidades seriam distintamente percebidas e processadas? Que características de imagens estáticas com algum movimento representado possibilitariam a sua percepção em um meio em que o movimento não existe?

A fotografia de uma bailarina em passo de dança pode ser facilmente reconhecida como em movimento. Da mesma maneira, duas pinturas figurativas representando bailarinas em distintos movimentos corporais podem ser rapidamente diferenciadas. Imagens artísticas com representação de movimento são comuns na história das artes visuais. Diferentes recursos vêm sendo utilizados pelos artistas para induzir, sugerir, evidenciar e representar fielmente o movimento em obras de arte bidimensionais estáticas (pinturas, desenhos, fotografias, etc.). Que recursos seriam utilizados para representar fielmente movimentos de objetos e seres vivos no plano bidimensional?

\section{A representação de movimento em imagens estáticas}

Em diferentes períodos e tempos históricos o homem esteve representando mais ou menos fielmente o mundo tridimensional através de desenhos e pinturas. Parte dessas representações bidimensionais vem sendo elaborada esteticamente, segundo critérios e recursos que, objetivamente, possibilitam imitar o mundo real; desta maneira, cria-se, no plano bidimensional, uma ilusão que aparenta ou retrata uma faceta do ambiente real.

Inúmeras são as possibilidades de representação de espaço tridimensional nas artes visuais. Entretanto, quantos e quais seriam os movimentos presentes numa obra de arte: movimentos reais, sugestões de movimentos ou ilusões que suscitam movimentos? Existem critérios para a representação de movimento nas artes visuais? Qual seria o papel dos movimentos oculares e do próprio movimento do corpo na percepção de movimento?

Artistas da Op Arte, como Bridget Riley, usando simples padrões em branco e preto têm criado ilusões vívidas de movimento em pinturas estáticas. Foi constatado que tais ilu- 
sões são devidas aos movimentos sacádicos dos olhos, que geram um sinal de movimento semelhante aos efeitos perceptuais experienciados pelos sujeitos. Junto de evidência computacional foi apontado que a ilusão ocorre em função dos próprios deslocamentos involuntários de partes da imagem ocasionados pelos movimentos dos olhos (Zanker \& Walker, 2004). Mesmo restringindo o campo de visão e pedindo para os sujeitos fixarem os olhos em pontos especificamente delimitados da pintura, tais pequenos movimentos oculares continuaram ocorrendo (Zanker, 2004).

Os pequenos deslocamentos de imagens podem gerar padrões de sinais de movimento em rede, os quais podem ser suficientes, mas não exclusivos, para explicar esta ilusão. Os mecanismos fisiológicos e de percepção de ilusão de movimento da Op Arte são matéria de debate científico. Recentemente, foi sugerido que a ilusão pode também ser devida a um enfraquecimento da imagem após os movimentos dos olhos; os vislumbres e deformações nas imagens se devem a flutuações de acomodação ocular (Zanker \& Walker, 2004). Zanker, Doyle e Walker (2003) argumentaram que diferentes autores focalizaram distintos aspectos de um dado estímulo, o que torna difícil definir como se processa essa percepção de movimento. Ao invés de usar alternativas excludentes para explicar a ilusão de movimento, deveria se aceitar uma variedade de causas que podem levar a um efeito igual, similar ou discordante.

Quantas e quais seriam as maneiras de sugerir movimento em imagens estáticas? Que recursos estéticos são utilizados pelos artistas plásticos para representar o movimento, principalmente quando ele ocorre em imagens figurativas (desenhos, pinturas e fotografias)? Existem técnicas definidas que garantem a representação de movimento? Em virtude da pluralidade da produção artística ocorrida principalmente na terceira década do século passado, quando provavelmente surgiu a Arte Contemporânea, muitas são as formas de representar e utilizar o movimento nas artes plásticas. Na maioria das vezes não só um, mas vários recursos estão presentes em uma mesma obra de arte.

Em algumas expressões artísticas (Arte Futurista, Arte Cinética, Op Arte, Happenings, etc.) o movimento é o objeto de estudo do artista plástico. Em outras, ele aparece como parte integrante da obra sem ser o foco central do artista. Em grande parte dos trabalhos artísticos do tipo pinturas e desenhos não só um, mas vários recursos de representação movimento estão presentes.

O movimento nas artes visuais. Desenhos, fotografias e pinturas só existem em espaços bidimensionais delimitados. Em outras expressões das artes visuais o próprio espaço ocupado pela obra a caracteriza: as instalações, as esculturas e os objetos artísticos estão inseridos num espaço do mundo das três dimensões, que pode ser percorrido pelo expectador. Dependendo do tamanho de uma obra bidimensional o expectador terá de se mover um pouco para observá-la; o expectador percorre, necessariamente, um espaço ao redor de esculturas e objetos durante a sua observação. Estas observações ilustram que, embora não fazendo parte da obra, o movimento pode ser fundamental durante o episódio estético, mesmo não sendo ele o objeto de estudo do artista. Nas artes visuais deve-se pensar na existência de relações de movimento entre obra-expectador.

As relações de movimento mostram que a interação dos observadores com determinadas obras de arte é fundamental. Essas interações podem gerar movimentos reais ou induzir a uma percepção de movimento por meio de representações que podem ser ilusórias, sutis, diretas, induzidas, participativas. Por exemplo, as relações de movimento podem ilustrar o pluralismo conceitual da escultura moderna através dos objetos móveis de Alexander Calder, que evocam no observador um volume virtual quando movimentados; e nas esculturas metálicas polidas de Brancusi que, em virtude da sua constituição, parecem modificar os absolutos da sua própria forma geométrica por meio de formas distorcidas de luz e de sombra refletidas a partir do ambiente em que estão sendo contempladas (Krauss, 2001).

A experiência do mundo tem um importante significado na criação e percepção estética. Representações pictóricas de movimentos próprios e de objetos em movimento devem ativar mecanismos de percepção de movimentos verdadeiros, podendo revelar a natureza da percepção do movimento - salvo algumas distinções da percepção que acontecem a partir do mundo real (Braddick, 1995). Evidências psicofísicas sugerem que no mundo tridimensional o sistema visual pode gerar um sinal específico no curso de um objeto em movimento entre os dois olhos e, com o cruzamento de informações, estabelecer a sua trajetória no espaço. Isso seria impossível de acontecer numa imagem de algo em movimento que foi "paralisado" numa pintura.

A percepção do movimento numa pintura figurativa pode depender da maneira de representar utilizada pelos pintores (Braddick, 1995): a imagem deve sugerir a trajetória do objeto e propiciar o reconhecimento da forma e textura cinética do que está em movimento. A forma cinética se refere às propriedades dinâmicas ou características dos objetos ou eventos representativos numa imagem, que são usados para a informação do movimento e reconhecimento de objetos biológicos e coisas a eles associados, estando por isso, também relacionada à interpretação pessoal de cada indivíduo. A textura cinética leva em conta a somatória ou conjunto de efeitos visuais da pintura, que contribuem para a caracterização do movimento. Além disso, na composição de uma imagem, as relações espaciais entre as figuras também podem suscitar movimento: estrategicamente posicionadas, elas permitem o estabelecimento de relações entre partes da imagem, efetivando um movimento no todo. Outra importante característica é a percepção da estrutura 3-D do objeto em movimento, o que envolve necessariamente experiências passadas e memória de eventos.

O controle e a capacidade de fixar os olhos no movimento, ou em pontos de maior interesse, e as informações gera- 
das pelo próprio movimento do observador também são importantes para percepção do movimento em uma imagem. O controle de movimentos exercido pelo observador faz parte da percepção cinestésica: os movimentos dos olhos, da cabeça ou do corpo são transmitidos ao centro sensorial motor do cérebro, e os seus feedbacks influenciam na percepção visual. Mover a cabeça induz o sentido da visão a também atribuir visualmente movimento à cabeça, e a perceber o ambiente como se fosse imóvel (Arnheim, 1980). Fatores cinestésicos podem sozinhos dar a sensação de movimento, independentemente das questões relacionadas à relatividade existente entre o "referencial” e o “observador".

Para Arnheim (1980), que propõe uma análise gestáltica da composição de obras de arte, outros dois fatores estão relacionados à experiência visual do movimento. O primeiro, o movimento físico, refere-se àquilo que se move, o que não necessariamente pode corresponder ao que acontece nos olhos e na percepção. Já o segundo, o movimento ótico refere-se àquilo é projetado do ambiente no campo visual do olho, e que é deslocado na retina. Tal deslocamento acontece quando o observador não segue os movimentos dos objetos percebidos. Assim, quando o olhar se fixa num objeto em movimento, o seu movimento físico pode ser considerado como uma parada ótica. Ao olhar esse objeto pintado em um quadro, cada vez que a fixação do olhar muda, o quadro todo se move nas retinas em direção oposta - algo que não é refletido na experiência perceptiva, ou seja, não percebido pelo observador.

Existem ainda os fatores especificamente visuais dentro do campo perceptivo. Os objetos no campo visual são vistos numa relação hierárquica de dependência (Arnheim, 1980). Pondo de lado o movimento, a organização espontânea do campo visual atribui a certos objetos o papel de moldura de referência, da qual os outros dependem. Por exemplo, para uma bailarina dançando, a moldura é o palco. Num deslocamento, a moldura tende a ser percebida como imóvel e a bailarina em movimento - o mesmo se daria numa pintura desta cena, pois haveria uma dependência entre ambos. Assim, onde não existe dependência, os objetos podem ser vistos movendo-se simetricamente, aproximando-se ou afastandose uns dos outros.

Cutting (2002) procurou estabelecer paralelos na representação do movimento na arte, na ciência e na cultura popular estudando imagens estáticas (pinturas, desenhos, fotografias e cartoons), utilizando obras de arte pertencentes a diferentes momentos históricos, para ilustrar seu postulado teórico. Embora tenha encontrado concordâncias nas descrições de movimento entre diferentes autores, salientou que com exceção feita aos trabalhos da Arte Cinética, poucas técnicas têm sido usadas para representar movimento nessas distintas áreas. Indagando como descrever o movimento num meio onde ele não existe e explorando uma "tipologia" de representação do movimento, apresentou o que seriam os caminhos para representar o movimento e os critérios para julgá-los.
Para Cutting (2002), os artistas plásticos vêm utilizando cinco diferentes recursos artísticos de representação de movimento. (1) Equilíbrio dinâmico: refere-se ao contraponto e às posições entre membros do corpo e vestimentas, que provocam assimetrias na figura. (2) Imagens estroboscópicas: imagens seqüenciadas de um objeto numa mesma imagem podem, em conjunto, evocar movimento. (3) Imagens obscurecidas ou desfocalizadas: consiste em fixar uma parte do objeto e obscurecer até certo ponto outras partes da imagem. (4) Inclinação (deformação da imagem): a inclinação de um objeto em movimento pode descrever a direção do seu movimento, principalmente quando ele é representado na forma inclinada, como em carros, trens, etc. (5) Linhas de ação (setas, tiras e vetores): é a utilização de setas vetoriais na imagem com o intuito de indicar o movimento que já aconteceu. A eficiência desses métodos de representação pode ser verificada através de quatro critérios, que dizem que uma imagem estática apresenta movimento quando ela: é capaz de evocar sensação de movimento, representa claramente o objeto em movimento, e indica a direção e a intensidade de um movimento.

Podem ser chamadas de metáforas as representações do movimento, porque elas não são as formas reais de percebê-lo no mundo real (Cutting, 2002). Certamente, existem nas artes visuais outros recursos de sugestão de movimento em imagens bidimensionais: o movimento não-intencional e o movimento intencional. No movimento não-intencional os arranjos das partes da obra podem não ter sido elaborados para dar a impressão de movimento, mas podem suscitar movimento no seu todo (Gestalt). Já no movimento intencional as partes da obra de arte estão integradas para assegurar algum movimento, ou elas literalmente retratam de forma objetiva um movimento real do mundo tridimensional. Embora esses tipos de representação possam usar diferentes recursos visuais, ambos podem ocorrer simultaneamente numa mesma obra, por não serem excludentes. A compreensão das diferenças entre estes movimentos pode ser facilitada com exemplos: uma pintura não-representacional (imagem abstrata), em que a composição de cores e linhas dispostas numa cadência característica sugere pouco movimento; uma imagem representativa fotográfica de um menino chutando uma bola a certa distância da trave de um gol sugere muito movimento.

Levando-se em conta a relação da obra com o referente, com o objeto que a imagem representa, há três tipos fundamentais de imagem: as não-representativas, as figurativas e as simbólicas (Santaella \& Nöth, 2001). As não-representativas, comumente chamadas de abstratas, estão reduzidas a elementos puros como, cores, manchas, brilhos, ritmo e movimento, e não representam nada que está fora delas. As figurativas transpõem para o plano bidimensional ou criam no espaço tridimensional réplicas de objetos preexistentes, representando com maior ou menor ambigüidade objetos ou situações que podem ser reconhecidos. As simbólicas, mesmo que sendo figurativas, representam algo abstrato e geral. 
Fisicamente todas as coisas e acontecimentos localizam-se no espaço-tempo. E a distinção entre coisas móveis de imóveis pode ser evidente, porém seria a mesma entre atemporalidade e tempo (Arnheim, 1980)? A experiência da passagem do tempo distinguiria, por exemplo, os movimentos de uma bailarina no palco e a pintura de um balé? Quando a bailarina salta pelo palco há um lapso de tempo que pode ser percebido como presente. Mas a faixa que o presente abrange pode ser medida? Da mesma forma, a pintura reflete qual "lapso" de tempo? Este lapso seria o mesmo de uma fotografia da sua coreografia? Pode-se dizer que a ação da bailarina é percebida como uma seqüência de fases, que pode conter uma orientação mais ou menos predizível. Esta ação não seria exatamente uma experiência temporal, mas espacial - o que poderia ser particularmente diferente se houvesse no balé a presença de um bailarino para segurá-la no momento de um grande salto, evitando uma queda. Neste caso, haveria também a expectativa ou o suspense incorporado ao evento. Provavelmente tal "fator" não estaria presente numa pintura, muito embora a cena pudesse conter os mesmos elementos.

Numa pintura, a cena é captada como um todo. Antes do advento da fotografia, a cena representava o momento artístico. Ela era caracterizada por gestos, posturas e arranjos de pessoas e objetos na chamada cena pictórica. Somados, seus elementos refletiam um momento, sugerindo como ele teria se desdobrado, isto é, uma passagem de tempo. A maneira de compor os elementos visuais de uma escultura ou um quadro representaria intervalos de tempo numa narrativa, que contextualizaria a seqüência lógica dos fatos num espaço-tempo (Krauss, 2001). Porém, com a tecnologia moderna podem ser registrados instantes fotográficos de objetos em velocidades incontáveis. Dependendo do intervalo de tempo registrado, instantes muito breves não podem ser "capturados" pelos olhos, e vários instantes seriam percebidos como um único. Que momento seria esse e qual movimento ele representaria? Pode-se supor que o olho não capte a mesma coisa de uma mesma imagem de instante a instante. Isso pode indicar que um instante pode falsificar uma verdade psicológica, ou seja, a percepção psicológica. Faz-se necessário diferenciar o que estamos acostumados a ver nos dias de hoje, pois a nossa visão pode ter sido capturada pela imagem estroboscópica (Cutting, 2002). Uma cena, foto ou momento capturado de um filme ou anúncio poderiam capturar uma verdade psicológica que o instante não poderia capturar.

Se por um lado o espaço pictórico é bastante ressaltado e discutido por estudiosos das artes visuais, pouco se fala sobre o tempo pictórico. Cutting (2002) argumentou que o tempo estaria focalizado na narrativa, mas ele não tem sido representado como o espaço. Estaríamos acostumados a capturar imagens instantâneas nos dias atuais, independentemente do fato do instante poder "não existir". Como exemplo ilustrativo, pode ser citada a pintura intitulada Action Painting de Tansey (1981), na qual há alguém pintando um acidente de carro com uma roda que se desprendeu e está se movendo para cima. A impossibilidade de alguém estar pintando uma roda desprendida no espaço ilustra o que hoje pode ser banal, frente aos grandes avanços tecnológicos que redimensionaram as relações espaço-tempo.

\section{O tempo subjetivo em imagens em movimento}

Os movimentos revelam uma série de localizações espaciais, indicando ao observador padrões de mudanças. A rapidez dessas mudanças no tempo pode gerar variados graus de percepção temporal, que promovem alterações na percepção do tempo. As características destes tipos de estímulos visuais têm também contribuído com os estudos de tempo subjetivo.

Experimentalmente, o tempo subjetivo pode ser analisado em termos de estimação (Fraisse, 1984), que está baseada na quantidade de mudanças percebidas pelo sujeito. Há certa tendência no processo de estimar o tempo: quanto maiores são as mudanças e o número de estímulos ocorridos por unidade de tempo, maior é a duração do evento para o sujeito (Zakay, 1990). Tanto a duração relembrada quanto a duração experienciada têm sido enfatizadas nas pesquisas de tempo subjetivo. Essas duas maneiras de estudar a questão temporal definem os paradigmas temporais: o retrospectivo no qual o sujeito não sabe que irá fazer uma estimação temporal (duração relembrada) e o prospectivo no qual ele tem a informação de que fará estimações temporais (duração experienciada).

Nas pesquisas de tempo subjetivo, a natureza da estimulação, as características do intervalo de tempo analisado, bem como a sua intensidade e modalidade podem envolver diferentes processamentos temporais, que podem resultar em alterações nas estimações temporais para mais (superestimações) ou para menos (subestimações). Isso porque o padrão de experiências temporais e suas relações com os eventos do mundo objetivo dependem do contexto no qual estão inseridos (Bueno, 1985).

No paradigma prospectivo, uma série de experimentos com imagens de quadrados exibidos numa tela de alta resolução mostraram que os estímulos parados foram julgados apuradamente, e os em movimento superestimados (Brown, 1995). Quanto mais rápidos os estímulos, maiores foram as superestimações temporais: os movimentos rápidos alongaram a percepção temporal em maior proporção que os menos velozes, algo provavelmente modulado pela duração dos estímulos. Entretanto, apesar de no seu transcorrer os estímulos mais rápidos conterem mais mudanças que os mais lentos, o número de estímulos usados num mesmo experimento suscitou uma limitada influência nos julgamentos de tempo. Independentemente desses fatos, intervalos curtos tendem a ser superestimados e os longos subestimados, mesmo utilizando distintos métodos de estimação temporal (Brown, 1995).

Contrariamente, Predebon (2002a) mostrou que no paradigma retrospectivo os estímulos com movimento mais 
rápido foram julgados mais curtos que os mais lentos. Foi salientado que, diferentemente do paradigma prospectivo, no qual a atenção dos sujeitos é voltada ao tempo, no retrospectivo a atenção está mais orientada às características não temporais do evento, envolvendo uma descrição mais holística ou global dos intervalos de um dado período de tempo. Assim, os movimentos mais rápidos, por percorrerem em menor tempo a trajetória experimental, podem alterar em maior proporção a direção e aceleração de seus movimentos e, conseqüentemente, ocasionar maiores mudanças (marcações temporais) num mesmo intervalo de tempo. Entretanto, nem todas as características de um estímulo influenciam diretamente a estimação temporal: somente aqueles que possuem saliência ou representatividade no contexto experimental. Isso quer dizer também que, se ocorrem muitas mudanças no estímulo, no total, elas podem se tornar pouco significativas, indicando mudanças pequenas no contexto cognitivo (Predebon, 2002a). Segundo Poynter (1989), nos julgamentos temporais de intervalos cheios as características dos estímulos servem como marcadores da experiência temporal, porque no processamento destes eventos são geradas referências temporais na memória com a qual é reconstruída a duração de um período de tempo.

Neste sentido é importante falar do movimento em relação a um campo visual de observação. Foi verificado que a eficiência do processamento visual aumenta se os elementos caírem no campo visual central (região irradiada), onde a atenção é dirigida (Predebon, 2002b). Como nem todos os elementos podem cair nesta área do campo é de se esperar que nem todos os elementos sejam processados da mesma maneira. Mudanças na localização espacial devem aumentar quando o estimulo está em movimento, e serem mais facilmente processadas, se caírem dentro de uma região de campo visual menor. Provavelmente, diferentes estratégias de observação existam em decorrência dos padrões de movimentos oculares presentes em situações próximas ou distantes.

Não seria o tamanho físico de um estímulo visual em movimento o único responsável pelas alterações nas estimações temporais, mas a densidade de informação por unidade de campo visual, a arquitetura do estímulo. Além disso, dependendo da localização dos estímulos, diferentes perspectivas de interpretação devem ser adotadas: como o espaço exerce efeito no tempo percebido, existe possibilidade de um dos hemisférios cerebrais ser superior ao outro no processamento temporal (Grondin, 2003). Mais informações a respeito do efeito do tamanho do campo visual e a percepção temporal podem ser encontradas em Mitchell e Davis (1987), Bokbo, Bobko e Davis (1986) e DeLong (1981).

Muitos teóricos têm afirmado que a percepção do tempo pode ser compreendida como a percepção de mudanças nos estímulos, e que tais mudanças podem causar alongamento da percepção temporal. Realmente, a experiência temporal depende da quantidade de informação temporal presente num determinado intervalo de tempo, a qual é percebida como uma seqüência de eventos em sucessão e mudança (Michon,
1985). Assim, quando se estudam estímulos visuais, parados ou em movimento, é necessário levar em consideração as medidas reais de velocidade, tempo e espaço, e os seus possíveis efeitos na percepção e cognição; mais ainda, deve-se pensar em representações quando se analisam imagens estáticas que retratam ou sugerem algum movimento.

\section{O tempo subjetivo em imagens estáticas}

Imagens estáticas vêm sendo empregadas em estudos de percepção subjetiva de tempo, visando comparar como ocorre a sua percepção em relação a imagens que apresentam movimentos em diferentes intensidades (Brown, 1995; Predebon, 2002a; Predebon 2002b). Entretanto, não têm sido encontrados, na literatura de tempo subjetivo, dados a respeito de como imagens estáticas que representam algum movimento podem afetar a estimação temporal dos sujeitos.

Nather e Bueno (2006), utilizando fotografias de objetos representando bailarinas em duas diferentes posições (uma sentada e a outra em posição de dança) encontraram diferenças nas estimações temporais entre as duas imagens: a bailarina sentada foi estimada com menor duração temporal que aquela em passo de balé, embora o tempo de exposição de ambas tenha sido o mesmo. Além disso, as duas imagens foram subestimadas em relação ao tempo real de exposição.

Estes resultados concordaram com um estudo no qual duas pinturas de bailarinas do artista impressionista Edgar Degas, reconhecido mundialmente por representar movimentos dos corpos humanos, foram estimadas com durações distintas: a pintura da bailarina parada foi estimada com menor duração que aquela em passo de balé (Nather \& Bueno, 2005). Tanto no trabalho com as fotografias de bailarinas (Nather \& Bueno, 2006), quanto com as pinturas de Degas (Nather \& Bueno, 2005), foi verificada a tendência de os participantes julgarem as imagens das bailarinas em movimento como sendo mais complexas e agradáveis que as bailarinas paradas.

A aproximação dos resultados de estudos comparando imagens estáticas e imagens em movimento (Brown, 1995; Predebon 2002a), e imagens estáticas com sugestões de movimento em diferentes intensidades de Nather e Bueno (2005, 2006) sugere a existência de processos e mecanismos de percepção correlatos. Entretanto, um estudo experimental com uma quantificação (mensuração) de movimento presente numa imagem pode elucidar esta percepção diferenciada de movimento? Por exemplo, imagens de uma bailarina parada, iniciando uma dança, dançando ou uma em postura de final de uma coreografia de balé seriam diferencialmente percebidas? Como mensurar estas diferentes representações e percepções de movimento?

Segundo Nather (2006), que elaborou uma Escala de Representação de Movimento (ERM) a partir da coleção de esculturas de bailarinas de Edgar Degas da coleção do Museu de Arte de São Paulo (MASP), os diferentes movimentos corporais representados foram distintamente percebidos e pon- 
tuados por bailarinos e estudantes universitários não treinados em dança. Esta pontuação de movimentos para as esculturas foi acompanhada por estimações temporais distintas em procedimentos experimentais semelhantes àqueles de estudos anteriores (Nather \& Bueno, 2005, 2006). Imagens de bailarinas paradas foram estimadas com menor duração que aquelas com movimentos intermediários e estas estimadas com menor duração que aquelas com maiores pontuações. Movimentos corporais mais intensos tenderam a ser superestimados temporalmente; esculturas de corpos parados tenderam a ser subestimados.

Tais resultados apóiam o emprego de imagens estáticas com movimento figurativo representado: nelas há implícita uma representação mais ou menos fiel do mundo tridimensional. Assim, a utilização de imagens figurativas, segundo critérios de representação de movimento apontados na literatura para imagens estáticas (Bradicck, 1995; Cutting, 2002), pode garantir que os dados da percepção subjetiva de tempo sejam colhidos a partir de estímulos visuais apropriados, como as obras de arte, uma vez que existe uma diversidade de recursos para induzir movimento num meio onde ele não existe.

A informação visual e a percepção de movimento serão melhores compreendidas quando se souber mais a respeito das características dos sinais visuais, que incluem o tempo necessário para sua integração ou segregação, e o seu impacto nos julgamentos de tempo. Neste sentido, com o estudo da percepção de movimento poderá ser analisada a cognição de processos que estão combinados; ou seja, sensações e percepções internas e externas, que ocorrem em sistemas e níveis perceptuais distintos. Para tanto, os trabalhos que utilizam o movimento como medida de tempo subjetivo devem levar em consideração não só fatores puramente físicos - como a velocidade, o tempo e o espaço - mas também a percepção e a memória.

\section{Referências}

Alderson, G. J. K., \& Whiting, H. T. A. (1974). Prediction of linear motion. Human Factors, 16, 495-502.

Algom, D., \& Cohen-Raz, L. (1987). Sensory and cognitive factors in the processing of visual velocity. Journal of Experimental Psychology: Human Perception and Performance, 13, 3-13.

Arnheim R. (1980). Arte e percepção visual: uma psicologia da visão criadora. São Paulo: Pioneira \& EDUSP.

Aymoz, C., \& Viviani, P. (2004). Perceptual asynchronies for biological and nonbiological visual events. Vision Research, 44, 1547-1563.

Bedell, H. E., Chung, S. T. L., Ogmen, H., \& Patel, S. S. (2003). Color and motion: which is the tortoise and which is the hare? Vision Research, 43, 2403-2412.

Berlyne, D. E. (1974). The new experimental aesthetics. In D. E. Berlyne (Org.), Studies in the new experimental aesthetics (pp. 1-25). Toronto: University of Toronto.

Bobko, D. J., Bobko, P., \& Davis, M. A. (1986). Effect of visual display scale on duration estimates. Human Factors, 28(2), 153-158.
Braddick, O. (1995). The many faces of motion perception. In O. Braddick (Org.), The artful eye (pp. 205-231). Oxford: Oxford University Press.

Brown, S. W. (1995). Time, change, and motion: the effects of stimulus movement on temporal perception. Perception and Psychophysics, 1, 105-116.

Bueno, J. L. O. (1985). A questão do tempo. In A. Jacquemin (Org.), XV Reunião Anual de Psicologia (pp. 196-197). Ribeirão Preto: Sociedade Brasileira de Psicologia.

Cutting, J. E. (2000). Images, imagination, and movement: pictorial representations and their development in the work of James Gibson. Perception, 29, 635-648.

Cutting, J. E. (2002). Representing motion in a static image: constraints and parallels in art, science, and popular culture. Perception, 31(10), 1165-1193.

DeLong, A. J. (1981). Phenomenological space-time: toward an experiential relativity. Science, 213, 681-683.

Ehrenstein, W. (2003). Basics of seeing motion. Arquivos Brasileiros de Oftalmologia, 66, 44-52.

Ellingstad, V. S., \& Heimstra, N. W. (1969). Velocity-time estimation as a function of target speed and concealment extent. Human Factors, 11, 305-312.

Fraisse, P. (1984). Perception and estimation of time. Annual Review of Psychology, 35, 1-36.

Gallese, V., Fadiga, L., Fogassi, L., \& Rizzolatti, G. (1996). Action recognition in the premotor cortex. Brain, 119, 593-609.

Gallese, V., Fadiga, L., Fogassi, L., \& Rizzolatti, G. (2002). Action representation and the inferior parietal lobule. In W. Prinz \& B. Hommel (Orgs.), Common mechanisms in perception and action: attention and performance (pp. 247266). Oxford: Oxford University Press.

Grondin, S. (2003). Processing time between visual events. Arquivos Brasileiros de Oftalmologia, 66, 96-104.

Hellmann, A. (1996). Auditory perception of approaching sound sources, and time-of-arrival judgements. Tese de Doutorado não-publicada, Universidade de Bochum, Alemanha.

Kellman, P. J. (1995). Ontogenesis of space and motion perception. In W. Epstein \& S. Rogers (Orgs.), Perception of space and motion (pp. 327364). Wisconsin: Madison Academic.

Krauss, R. E. (2001). Caminhos da escultura moderna. São Paulo: Martins Fontes.

Lappin, J. S., Bell, H. H., Harm, O. J., \& Kottas, B. (1975). On the relation between time and space in the visual discrimination of velocity. Journal of Experimental Psychology: Human Perception and Performance, 1(4), 383-394.

Leisler, D., Stern, E., \& Meyer, J. (1991). Mean velocity and total time estimation effects of order and proportions. Journal of Environmental Psychology, 11, 347-358.

Michon, J. A. (1985). The complete time experimenter. In J. A. Michon, \& J. L. Jackson (Orgs.), Time, mind, and behavior (pp. 20-52). New York: Springer-Verlag.

Mitchell, C., \& Davis, R. (1987). The perception of time in scale model environments. Perception, 16, 5-16.

Morin, R. E., Grant, D. A., \& Nystrom, C. O. (1956). Temporal predictions of motion inferred from intermittently viewed light stimuli. The Journal of General Psychology, 55, 59-71.

Nakayama, K. (1985). Biological image motion processing: a review. Vision Research, 25(5), 625-660.

Nather, F. C. (2006). Percepção de movimento e tempo subjetivo nas artes visuais. Tese de Doutorado não-publicada, Universidade de São Paulo, Ribeirão Preto. 
Nather, F. C., \& Bueno, J. L. O. (2005). Percepção de movimento e tempo subjetivo em pinturas figurativas de Edgar Degas [Resumo]. In Sociedade Brasileira de Psicologia (Org.), XXXV Reunião Anual de Psicologia. Resumos (p. 67). Curitiba: Autor.

Nather, F. C., \& Bueno, J. L. O. (2006). Efeitos de imagens estáticas com diferentes representações de movimento sobre a percepção subjetiva de tempo. Psicologia: Reflexão \& Crítica, 19(2), $217-$ 224.

Peterken, C., Brown, B., \& Bowman, K. (1991). Predicting the future position of a moving target. Perception, 20, 5-16.

Poynter, W. D. (1989). Judging the duration of time intervals: a process of remembering segments of experience. In I. Levin \& D. Zakay (Orgs.), Time and human cognition: a life-span perspective (pp. 305-321). Amsterdan: Elsevier.

Predebon, J. (2002a). Stimulus motion and retrospective time judgments. Acta Phychologica, 109, 213-225.

Predebon, J. (2002b). Viewing distance and estimates of duration. Perceptual and Motor Skills, 95, 326-328.

Rizzolatti, G., Fadiga, L., Gallese, V., \& Fogassi, L. (1996). Action cortex and cognition of motor actions. Cognitive Brain Research, 3(2), 131141.
Rosenbaum, D. A. (1975). Perception and extrapolation of velocity and aceleration. Journal of Experimental Psychology: Human Perception and Performance, 1(4), 395-403.

Runeson, S. (1975). Visual prediction of collision with natural and nonnatural motion functions. Perception \& Psychophysics, 18, 261-266.

Santaella, L., \& Nöth, W. (2001). Imagem: cognição, semiótica, mídia. São Paulo: Iluminuras.

Viviani, P., \& Aymoz, C. (2001). Colour, form, and movement are not perceived simultaneously. Vision Research, 41, 2909-2918.

Yakimoff, N., Mateef, S., Ehrenstein, W., \& Hohnstein, J. (1993). Motion extrapolation performance: a linear model approach. Human Factors, 35, 501-510.

Zakay, D. (1990). The evasive art of subjective time measurement: some methodological dilemmas. In R. A. Block (Org.), Cognitive models of psychological time (pp. 59-84). Hillsdale, New Jersey: Erlbaum.

Zanker, J. (2004). Motion illusions in Op-art paintings. Spatial Vision, 17(1-2), $75-94$.

Zanker, J., Doyle, M., \& Walker, R. (2003). Gaze stability of observers watching Op art pictures. Perception, 32, 1037-1049.

Zanker, J., \& Walker, R. (2004). A new look at Op art: towards a simple explanation of illusory motion. Naturwissenschaften, 91, 149-156.

Francisco Carlos Nather, doutor em Psicobiologia pela Faculdade de Filosofia, Ciências e Letras de Ribeirão Preto da Universidade de São Paulo (SP), é professor no Departamento de Psicologia e Educação da mesma Universidade. Endereço para correspondência: Faculdade de Filosofia, Ciências e Letras; Departamento de Psicologia e Educação; Universidade de São Paulo; Avenida dos Bandeirantes, 3900; Ribeirão Preto, SP; CEP 14040-901. Tel.: (16) 602-3697. Fax: (16) 633-5668. E-mail: fnather@usp.br José Lino Oliveira Bueno, doutor em Psicologia Experimental, pela Universidade de São Paulo, é Professor Titular no Departamento de Psicologia e Educação da Faculdade de Filosofia, Ciências e Letras de Ribeirão Preto, Universidade de São Paulo.E-mail: jldobuen@ffclrp.usp.br 